University of Wollongong

Research Online

Faculty of Engineering and Information

Faculty of Engineering and Information

Sciences - Papers: Part A

Sciences

$1-1-2013$

Impact of chemical cleaning on the nanofiltration of pharmaceutically active compounds (PhACs): The role of cleaning temperature

Alexander Simon

University of Wollongong, asimon@uow.edu.au

William E. Price

University of Wollongong, wprice@uow.edu.au

Long D. Nghiem

University of Wollongong, longn@uow.edu.au

Follow this and additional works at: https://ro.uow.edu.au/eispapers

Part of the Engineering Commons, and the Science and Technology Studies Commons

Research Online is the open access institutional repository for the University of Wollongong. For further information contact the UOW Library: research-pubs@uow.edu.au 


\title{
Impact of chemical cleaning on the nanofiltration of pharmaceutically active compounds (PhACs): The role of cleaning temperature
}

\begin{abstract}
This study investigated the impact of chemical cleaning on the physicochemical properties of a nanofiltration membrane and its subsequent separation efficiency of inorganic salts and two pharmaceutically active compounds (PhACs), sulfamethoxazole and carbamazepine. Chemical cleaning was simulated by immersing virgin membrane samples in aqueous citric acid, sodium hydroxide $(\mathrm{NaOH})$, ethylenediaminetetraacetic-acid (EDTA) and sodium dodecyl sulphate (SDS) at various temperatures for $18 \mathrm{~h}$. The cleaning temperature did not exert any discernible impact on the surface charge of the NF270 membrane selected in this study. However, high cleaning temperatures were shown to either amplify or reduce the impact of chemical cleaning on several other membrane properties (including hydrophobicity, surface roughness and permeability) as well as the rejection of both inorganic salts and PhACs. The influence of chemical cleaning on the membrane surface roughness was enhanced at elevated cleaning temperatures. Similarly, at a high cleaning temperature, caustic and acidic cleaning caused a more significant increase in the membrane surface hydrophobicity than that at an ambient temperature. An increase in the cleaning temperature could also slightly amplify the decrease in the membrane permeability due to acidic cleaning. When a caustic cleaning solution ( $\mathrm{pH} 11.5)$ was used, the membrane permeability only varied slightly with the temperature. Results obtained from Fourier transform infrared spectroscopy (FTIR) analysis suggest that chemical cleaning even at a high temperature did not permanently alter the chemical composition of the membrane active or support layer. Indeed, the effects of chemical cleaning at a high temperature on the physicochemical properties of the membrane could be attributed to the conformational changes of the membrane polymeric matrix. Chemical cleaning using citric acid, SDS or EDTA at a high temperature resulted in a considerable increase in the rejection of salts and PhACs in their neutral form. On the other hand, caustic cleaning at an elevated temperature had no discernible impact on the rejection of inorganic salts and neutral PhACs. This is because caustic cleaning and an elevated cleaning temperature cause opposing effects on the rejection of these solutes. Chemical cleaning at all temperatures investigated in this study did not affect the removal of negatively charged sulfamethoxazole.
\end{abstract}

\section{Keywords}

active, pharmaceutically, nanofiltration, cleaning, chemical, impact, role, temperature, phacs, compounds

Disciplines

Engineering | Science and Technology Studies

\section{Publication Details}

Simon, A., Price, W. E. \& Nghiem, L. D. (2013). Impact of chemical cleaning on the nanofiltration of pharmaceutically active compounds (PhACs): The role of cleaning temperature. Journal of the Taiwan Institute of Chemical Engineers, 44 (5), 713-723. 


\title{
Impact of chemical cleaning on the nanofiltration of pharmaceutically active compounds (PhACs): The role of cleaning temperature
}

\author{
Jan 2013 \\ Revised Manuscript Submitted to \\ Journal of the Taiwan Institute of Chemical Engineers
}

\begin{abstract}
Alexander Simon ${ }^{1}$, William E. Price ${ }^{2}$, Long D. Nghiem ${ }^{1} *$
${ }^{1}$ School of Civil Mining and Environmental Engineering
\end{abstract}

The University of Wollongong, Wollongong, NSW 2522, Australia

${ }^{2}$ School of Chemistry

The University of Wollongong, Wollongong, NSW 2522, Australia

* Corresponding author: Long Duc Nghiem, Email longn@uow.edu.au; Tel: +61 242214590 


\section{Abstract}

This study investigated the impact of chemical cleaning on the physicochemical properties of a nanofiltration membrane and its subsequent separation efficiency of inorganic salts and two pharmaceutically active compounds (PhACs), sulfamethoxazole and carbamazepine. Chemical cleaning was simulated by immersing virgin membrane samples in aqueous citric acid, sodium hydroxide $(\mathrm{NaOH})$, ethylenediaminetetraacetic-acid (EDTA) and sodium dodecyl sulphate (SDS) at various temperatures for 18 hours. The cleaning temperature did not exert any discernible impact on the surface charge of the NF270 membrane selected in this study. However, high cleaning temperatures were shown to either amplify or reduce the impact of chemical cleaning on several other membrane properties (including hydrophobicity, surface roughness and permeability) as well as the rejection of both inorganic salts and PhACs. The influence of chemical cleaning on the membrane surface roughness was enhanced when the cleaning temperature increased. Similarly, at a high cleaning temperature, caustic and acidic cleaning caused a more significant increase in the membrane surface hydrophobicity than that an ambient temperature. An increase in the cleaning temperature could also slightly amplify the decrease in the membrane permeability due to acidic cleaning. When a caustic cleaning solution ( $\mathrm{pH}$ 11.5) was used, the membrane permeability only varied slightly with the temperature. Results obtained from Fourier transform infrared spectroscopy (FTIR) analysis suggest that chemical cleaning even at a high temperature did not permanently alter the chemical composition of the membrane active or support layer. Indeed, the effects of chemical cleaning at a high temperature on the physicochemical properties of the membrane could be attributed to the conformational changes of the membrane polymeric matrix. Chemical cleaning using acidic, SDS or EDTA cleaning solutions at a high temperature resulted in a considerable increase in the rejection of salts and PhACs in their neutral form. On the other hand, caustic cleaning at an elevated temperature had no discernible impact on the rejection of inorganic salts and neutral PhACs. This is because caustic cleaning and an elevated cleaning temperature cause opposing effects on the rejection of these solutes. Chemical cleaning at all temperatures investigated in this study did not affect the removal of negatively charged sulfamethoxazole.

Keywords: Chemical cleaning, caustic cleaning, acidic cleaning, temperature, nanofiltration, pharmaceutically active compounds (PhACs), water reuse. 


\section{Introduction}

Water reuse (or recycling) has been recognised as an attractive option to overcome freshwater scarcity, which has become a significant issue in many parts of the world. Water reuse involves advanced purification of reclaimed wastewater to provide additional water for a variety of beneficial uses, including drinking purposes. Recent advances in membrane science and process engineering have allowed nanofiltration (NF) and reverse osmosis (RO) membranes to become an integral part of numerous water reclamation plants around the world [1]. A major challenge in water reuse, particularly for indirect or direct potable purposes, is the reliable removal of health-concerning trace organic contaminants such as pharmaceutically active compounds (PhACs). These low molecular contaminants are widely detected in secondary treated effluent and sewage impacted water bodies [2-5]. The occurrence of PhACs in the aquatic environment is of significant concern given their high pharmaceutically active properties, which can cause possible adverse effects upon human health and the ecosystem [4-6]. Attempts to survey the concentration of PhACs and other trace organic contaminants in the aquatic environment in Europe [6], Asia [4, 7], and Australia [8] have identified a considerable level of ecological risks associated with their occurrence in raw sewage and sewage impacted water bodies such as rivers and lakes. In addition, little is known regarding the long-term impact of PhACs at trace levels on non-target organisms [9]. Although PhACs can be removed effectively by NF/RO separation processes [10-12], the reliability of the separation depends on the membrane surface condition, which can be modified by membrane fouling and chemical cleaning. Chemical cleaning reagents such as alkalis, acids, surfactants, metal chelaters and oxidisers are commonly used to remove inorganic, organic and biological matter from the membrane surface to restore the permeate flux. Although significant effects of chlorine, which is a strong oxidiser, on solute removal by $\mathrm{NF} / \mathrm{RO}$ membranes have been reported [13, 14], the impact of chemical cleaning, in particular due to caustic, acidic, surfactants and metal chelating reagents, on the rejection of trace organic contaminants is still poorly understood or explored in the literature [15].

In general, chemical cleaning is essential in any $\mathrm{NF} / \mathrm{RO}$ applications and can accelerate the membrane ageing process [16]. The impact of chemical cleaning on the membrane integrity depends on the cleaning concentration, cleaning solution composition, time of exposure, cleaning methodology and temperature. Increasing the cleaning solution temperature during the cleaning process is particularly attractive as it accelerates transport processes, chemical reactions and the solubility of various foulants [17]. Apart from chemical interactions with the 
membrane, high cleaning temperature may also further enhance the modification of the membrane properties [18].

The aim of this paper is to study the impact of chemical cleaning at different temperatures on the filtration behaviour of a NF membrane. Changes in the membrane properties, including surface charge, roughness, hydrophobicity and permeability due to different chemical cleaning conditions (i.e. cleaning reagents and temperature) were systematically characterised and related to the impact on the separation of inorganic salts and PhACs. The results provide further insight into the process of membrane ageing caused by excessive chemical cleaning.

\section{Material and Methods}

\subsection{Analytical Reagents}

All chemicals used in this study were of analytical grade and purchased from Sigma Aldrich (Castle Hill, NSW, Australia). Sodium hydroxide, citric acid, sodium dodecyl sulphate (SDS), and disodium ethylenediaminetetraacetic (EDTA) were used to simulate membrane cleaning using caustic, acidic, surfactant, and chelating reagents, respectively. These reagents are commonly used in industrial practice to mitigate organic, inorganic (scaling), and a combination of these two modes of fouling. The cleaning solutions were prepared by separately dissolving each reagent in Milli-Q water. Sulfamethoxazole and carbamazepine were selected as model PhACs for the filtration test in this study. The physicochemical properties of sulfamethoxazole and carbamazepine are shown in Table 1. A stock solution was prepared by diluting 1 g. $\mathrm{L}^{-1}$ of each compound in methanol. This stock solution was stored at $-18^{\circ} \mathrm{C}$ in the dark and was used within one month.

Table 1: Physiochemical properties of carbamazepine and sulfamethoxazole (data from SciFinder Scholar).

\begin{tabular}{|l|c|c|}
\hline Trace organic & Sulfamethoxazole \\
\hline Molecular structure & & \\
& &
\end{tabular}




\subsection{Nanofiltration Membrane}

The NF membrane NF270 (Dow FilmTec, Minneapolis, MN, USA) was used in this investigation. NF270 is a thin-film composite membrane made of semi-aromatic piperazine based polyamide skin layer on top of a microporouse polysulphone backing layer and has a relatively open pore structure (estimated average pore diameter of $0.84 \mathrm{~nm}$ ) [11] and a high water permeability (13.5 L.m $\left.\mathrm{m}^{-2} \mathrm{~h}^{-1} \mathrm{bar}^{-1}\right)$ [19]. According to the manufacturer, the molecular weight cut-off of the NF270 is between 200-300 Da. The recommended operating pH range is between $\mathrm{pH} 3$ and 10. However, for short-term (30 min) cleaning purposes, the $\mathrm{pH}$ can be extended to $\mathrm{pH} 1$ to 12 . The maximum operating temperature is $45{ }^{\circ} \mathrm{C}$, while it is not recommended exceeding $35^{\circ} \mathrm{C}$ when the membrane is used above $\mathrm{pH} 10$ [20]. Prior to the membrane integrity and filtration tests, the membrane samples were carefully rinsed with Milli-Q water to remove any protective layer and chemical residues. The NF270 has been used in several full-scale water purification plants in Europe for ground and surface water treatment [21].

\subsection{Filtration Setup and Experimental Protocol}

A laboratory-scale cross-flow stainless-steel NF/RO filtration system was used for filtration tests of virgin and cleaned membrane samples. A detailed description of this filtration system is available elsewhere [22].

In preparation for the filtration tests, the membrane samples were compacted in Milli-Q water at 18 bar until the permeate flux was constant. An electrolyte solution $(10 \mathrm{~L})$ containing $1 \mathrm{mM}$ $\mathrm{CaCl}_{2}, 20 \mathrm{mM} \mathrm{NaCl}$ and $1 \mathrm{mM} \mathrm{NaHCO}$ was used as a feed solution. Both sulfamethoxazole and carbamazepine were spiked into the feed reservoir at a concentration up to $750 \mu \mathrm{g} . \mathrm{L}^{-1}$ each. The feed $\mathrm{pH}$ was adjusted with $\mathrm{NaOH}(1 \mathrm{M})$ to $\mathrm{pH} 10$ and then stepwise reduced with $\mathrm{HCl}(1 \mathrm{M})$ to $\mathrm{pH}$ 4. The system was stabilised at each $\mathrm{pH}$ for at least one hour before feed and permeate samples were collected for analysis. Feed temperature, cross-flow velocity and

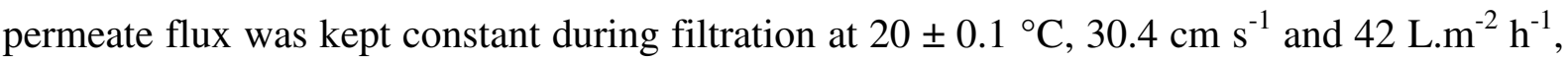
respectively.

\subsection{Cleaning Simulation}

Membrane cleaning was simulated by exposing the virgin membrane samples to different cleaning solutions at various temperatures. The temperature during the cleaning simulation was adjusted with a water bath on a platform shaker, which guaranteed an active transport of the cleaning reagent to the membrane surface. An exposure time of 18 hours was used to 
simulate repetitive membrane cleaning cycles and to accelerate membrane ageing. The membrane samples were subsequently removed from the solution and rinsed gently with Milli-Q water prior to use for filtration, and subsequent surface charge and permeability tests. This cleaning protocol corresponds to a membrane operation time of 4.5 or 9 years, if a cleaning process is conducted every 3 to 6 months for 1 hour, respectively. Each measurement was carried out on separate cleaned membrane samples.

To study the possible impacts of the cleaning temperature on the membrane performance and integrity, the cleaning temperature ranged from room temperature to slightly higher than those specified by the manufacturer. Membrane manufacturers usually specify the maximum limits for the use of chlorine, acidic and caustic reagents, but not the optimum concentration range of surfactants and metal chelating reagents despite their widespread application as key ingredients in commercial cleaning products $[23,24]$. The optimum concentration of EDTA has been reported to be between 1 and $10 \mathrm{mM}$ [25]. On the other hand, SDS has been reported to be most effective above the critical micelle concentration of SDS [25], which is approximately $8.36 \mathrm{mM}$ at $25^{\circ} \mathrm{C}$ [24].

The cleaning simulation used in this study differs from that in full-scale applications, where high concentrations, vigorous mixing (by a high cross-flow velocity) and cleaning sequences can also be used to improve the cleaning efficiency [26]. On the other hand, the fouling layer may shield the membrane from direct exposure to the cleaning reagents. Nevertheless, this experimental protocol appears to be the most appropriate testing regime in a laboratory environment to evaluate possible membrane degradation caused by chemical cleaning [13, 22 , 27-30].

\subsection{Membrane Characterisation}

\subsubsection{Zeta Potential}

Streaming potential of the virgin and cleaned membrane was conducted in $1 \mathrm{mM} \mathrm{KCl}$ using a SurPASS Electrokinetic Analyser (Anton Paar GmbH, Graz, Austria). The pH was adjusted by automatic titration of analytical grade hydrochloric acid and potassium hydroxide. The zeta potential was then calculated using the Fairbrother-Mastin approach. The streaming potential measurements were performed in a clamping cell, at 500 mbar and at room temperature $(20 \pm$ $1{ }^{\circ} \mathrm{C}$ ). All measurements were performed four times and the error was found to be less than 1 $\mathrm{mV}$. 


\subsubsection{Measurement of the Membrane Surface Roughness}

A multimode atomic force microscope (AFM) (Digital Instruments, Santa Barbara, CA, USA) was used to analyse the surface morphology before and after chemical cleaning. A surface area of $2 \mu \mathrm{m} \times 2 \mu \mathrm{m}$ with a resolution of $512 \times 512$ pixels was imaged at a scanning speed of $1 \mathrm{~Hz}$. The measurement was carried out in the air-tapping mode using an oxide sharpened SiN probe. The average surface roughness ( $\mathrm{Ra}$ ) was measured in triplicate on different locations of each membrane sample. Prior to the measurement, the membrane samples were dried in air.

\subsubsection{Contact Angle Measurement}

Prior to the contact angle measurement, the membrane samples were dried in air under a fume cover for approx 3 hours. The hydrophobicity was determined by placing several Milli-Q water drops on membrane samples using the standard sessile drop method. A Rame-Hart Goniometer (Model 250, Rame-Hart, Netcong, NJ) was used to measure the contact angle between the water-air interface. At least 5 droplets were applied onto membrane samples and the contact angle was measured on both sides of the droplet.

\subsubsection{Permeability}

A bench scale dead-end filtration system was used to measure the permeability of virgin and cleaned membrane. A detailed description of this dead-end filtration system is given elsewhere [31]. The system featured a stainless steel stirred cell with an active membrane surface area of $21.2 \mathrm{~cm}^{2}$. A Millipore stainless steel reservoir capable of $2.5 \mathrm{~L}$ feed solution was connected to the cell and instrument grade air was used to pressurize the system. A digital balance (Model Mettler Toledo, Ohio, USA) connected to a personal computer was used to measure the permeate flow. Prior to the measurement, the membrane was initially compacted for 1 hour using Milli-Q water at 6 bar and a permeability measurement was finally conducted at 5 bar and room temperature $\left(20 \pm 1^{\circ} \mathrm{C}\right)$.

\subsubsection{Fourier transform infrared spectroscopy analysis}

Fourier transform infrared spectroscopy (FTIR) analysis of virgin and chemically cleaned membranes were conducted using an IRAffinity-1 (Shimadzu, Kyoto, Japan). The instrument was equipped with a diamond crystal. The measured spectrum was between $700 \mathrm{~cm}^{-1}$ and $1750 \mathrm{~cm}^{-1}$. Each scan was performed 10 times at a resolution of $1 \mathrm{~cm}^{-1}$. 


\subsection{Analytical Method}

Carbamazepine and sulfamethoxazole were analysed with a Shimadzu HPLC system (Kyoto, Japan) equipped with a Discovery C18 column (with diameter, length and pore size of 4.6 $\mathrm{mm}, 300 \mathrm{~mm}$ and $5 \mu \mathrm{m}$, respectively). Analysed were measured with a UV-detector at a wavelength of $280 \mathrm{~nm}$. Two solutions premixed by HPLC grade acetonitrile (ACN) and a 25 $\mathrm{mM}$ buffer solution $\left(\mathrm{KH}_{2} \mathrm{PO}_{4}\right)$ were used for the mobile phase (Eluent A: $80 \% \mathrm{ACN} / 20 \%$ buffer solution and Eluent B: $20 \%$ ACN/80\% buffer solution). The flow rate was $0.7 \mathrm{~mL} . \mathrm{min}^{-}$ ${ }^{1}$ and the sample injection volume was $50 \mu \mathrm{L}$. The detection limit for sulfamethoxazole and carbamazepine using these conditions was approximately $20 \mu \mathrm{g} . \mathrm{L}^{-1}$ [32]. Six repetitive measurements of sulfamethoxazole and carbamazepine revealed a detection uncertainty at a concentration of $750 \mu \mathrm{g} . \mathrm{L}^{-1}$ of $0.6 \%$ and $0.4 \%$ and at a concentration of $20 \mu \mathrm{g} . \mathrm{L}^{-1}$ of $0.7 \%$ and $3.8 \%$ for this method, respectively. The analysis was carried out immediately after each filtration experiment.

\section{Results and Discussion}

\subsection{Impact on Membrane Properties}

\subsubsection{Surface Charge}

The impact of cleaning temperature on the membrane surface charge appears to be insignificant. When no cleaning reagents were used, exposing the NF270 membrane to MilliQ water at an elevated temperature (i.e. 35 or $50{ }^{\circ} \mathrm{C}$ ) resulted in only negligible changes in the zeta potential profile as a function of $\mathrm{pH}$ (Figure 1a). Exposure of the NF270 to a caustic cleaning solution $(\mathrm{pH} 11.5)$ at $50{ }^{\circ} \mathrm{C}$ for 18 hours resulted in a slightly more negatively charged surface at $\mathrm{pH}$ in the range of 6 to 10 than that of the virgin membrane or when a lower cleaning temperature (i.e. 20 or $35^{\circ} \mathrm{C}$ ) was used (Figure 1b). No discernible changes in the membrane surface charge could be seen after the membrane was exposed to an acidic cleaning solution or a solution containing SDS or EDTA at either 35 or $50{ }^{\circ} \mathrm{C}$ (Figure 1c-e). These results are consistent with previous studies by Al-Amoudi et al [27] and by Simon et al [22]. Al-Amoudi et al [27] reported no measurable impact of chemical cleaning on the surface charge of three NF membranes (namely DK, DL and HL) as the cleaning temperature was varied in the range from 20 to $34{ }^{\circ} \mathrm{C}$. Similarly, Simon et al [22] reported that chemical cleaning using acidic, surfactant and chelating reagents at various strengths had a negligible effect on the surface charge of the NF270 membrane. The membrane zeta potential is governed by the number and type of ionisable functional groups (such as amines and 
carboxyls) of the membrane surface [33]. Our results suggest that chemical cleaning either at ambient or elevated temperatures does not permanently and significantly alter the numbers density of the functional groups on the membrane active layer.

Figure 1: Membrane zeta potential before and after being exposed to a) Milli-Q water, b) $\mathrm{NaOH}(\mathrm{pH} \mathrm{11.5}), \mathrm{c})$ citric acidic ( $\mathrm{pH} 2), \mathrm{d}) \operatorname{SDS}(10 \mathrm{mM})$ and e) EDTA (5.4 mM) at 20, 35, and $50{ }^{\circ} \mathrm{C}$. The background electrolyte for the zeta potential measurement was $1 \mathrm{mM} \mathrm{KCl}$ at $20 \pm 1{ }^{\circ} \mathrm{C}$. Error bars show the measured standard deviation of three separate virgin membrane samples. 


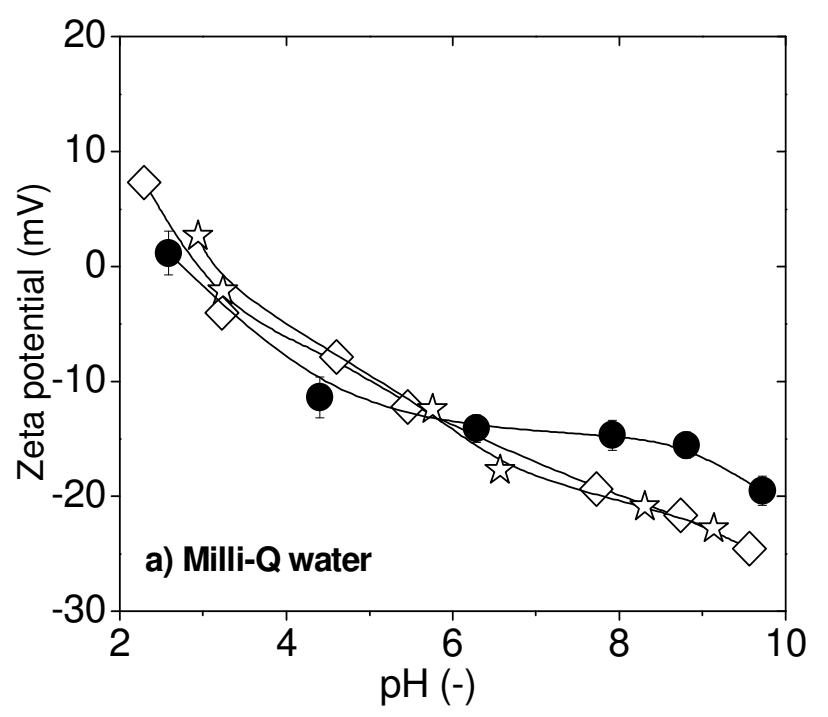

- Virgin NF270 membrane

$-\nabla$ - After cleaning at $20{ }^{\circ} \mathrm{C}$

$\checkmark$ After cleaning at $35^{\circ} \mathrm{C}$

- After cleaning at $50^{\circ} \mathrm{C}$
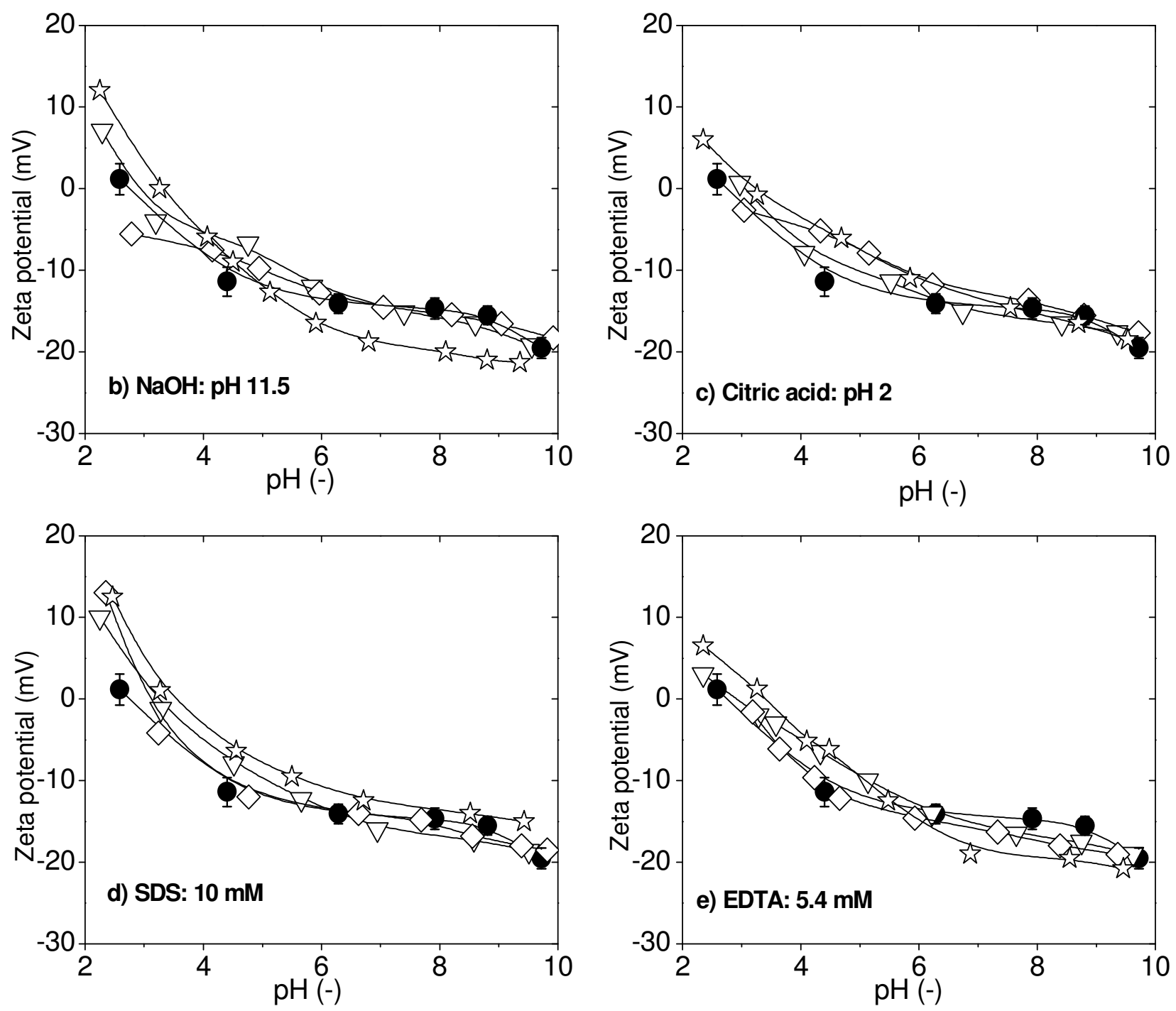

Figure 1 


\subsubsection{Surface Roughness}

The impact of chemical cleaning on the surface roughness of the NF270 membrane was increased when the cleaning temperature increased. The NF270 exposed to Milli-Q water at $20{ }^{\circ} \mathrm{C}$ membrane had a very smooth surface with an average surface roughness of $3.7 \mathrm{~nm}$, which is in good agreement with a previous study [13]. An increase in the cleaning temperature from 20 to $50{ }^{\circ} \mathrm{C}$ increased the surface roughness slightly when Milli-Q water and no reagents were used (Figure 2). However, when a caustic cleaning solution ( $\mathrm{pH} 11.5$ ) was used, the increase in roughness became dramatic and elevated cleaning temperatures (i.e. 35 and $50{ }^{\circ} \mathrm{C}$ ) further contributed to the increase in roughness. In contrast, the use of aqueous citric acid, SDS and EDTA at elevated temperatures (i.e. 35 and $50{ }^{\circ} \mathrm{C}$ ) also increased the surface roughness slightly, similar as Milli-Q water alone (Figure 2).

It appears that the elevated cleaning temperature and reagents increased the surface roughness by physical transformation of the membrane polymer. At elevated cleaning temperatures, the membrane polymer swells and a subsequent decrease in the cleaning temperature can shrink the membrane polymer $[18,34,35]$. This effect is known as membrane hysteresis and could subsequently affect the membrane roughness. Caustic cleaning can also result in the swelling of the membrane polymer by increasing the charge repulsion between functional groups of the same charge $[22,28]$. The severe increase in surface roughness by caustic cleaning at $50{ }^{\circ} \mathrm{C}$ could also influence the zeta potential measurement [36], causing a small variation in the membrane surface charge when a caustic cleaning solution was used as discussed above in section 3.1.1.

Figure 2: Membrane surface roughness before and after being exposed to Milli-Q water, $\mathrm{NaOH}(\mathrm{pH} \mathrm{11.5)}$, citric acidic (pH 2), SDS (10 mM) and EDTA (5.4 mM) at 20, 35 and 50 ${ }^{\circ} \mathrm{C}$. Scanning area, resolution and speed was $2 \times 2 \mu \mathrm{m}, 512 \times 512$ pixels and $1 \mathrm{~Hz}$, respectively. Error bars show standard deviation of three measurements of different sample locations. 


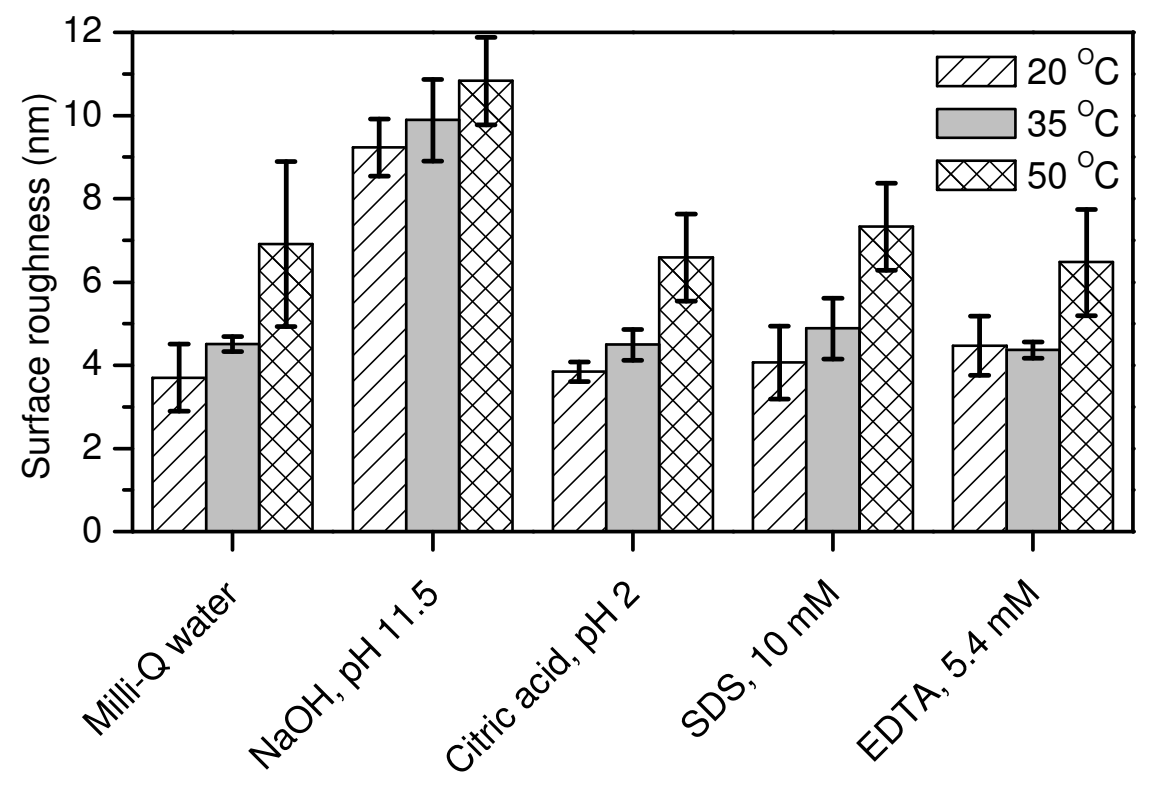

\subsubsection{Surface Hydrophobicity}

The membrane hydrophobicity can be determined by contact angle measurement of the membrane surface. The impact of chemical cleaning on the contact angle of the membrane surface was aggravated when the cleaning temperature increased (Figure 3). Although exposing the NF270 membrane to Milli-Q water at an elevated temperature (i.e. 35 and 50 ${ }^{\circ} \mathrm{C}$ ) only resulted in negligible changes in the membrane hydrophobicity, notable variation could be seen when either a caustic $(\mathrm{pH} 11.5)$ or acidic cleaning solution $(\mathrm{pH} 2)$ was used. A caustic cleaning solution at $50{ }^{\circ} \mathrm{C}$ resulted in a significant increase in the membrane hydrophobicity when compared with an intermediate cleaning temperature of 20 and $35{ }^{\circ} \mathrm{C}$, and especially with the hydrophobicity of the virgin membrane (Figure 3). An increase in the cleaning temperature to 35 and $50{ }^{\circ} \mathrm{C}$ of the acidic solution also led to a notable increase in the membrane hydrophobicity. On the other hand, when either SDS or EDTA was used, the impact of cleaning temperature on the surface hydrophobicity of the NF270 membrane was small and rather inconclusive. This is consistent with a previous study [22], in which no significant impact on the membrane hydrophobicity by SDS and EDTA at $35{ }^{\circ} \mathrm{C}$ and at various concentrations has been reported. Any variation in hydrophobicity may be governed by changes in either chemical and/or physical characteristics of the membrane surface in response to chemical cleaning. As discussed in section 3.1.1, chemical cleaning even at an elevated temperature did not result in any permanent changes in the charge of the membrane active layer. Therefore, the observed increase in the membrane contact angle during chemical cleaning at elevated temperatures is likely due to significant changes in the membrane 
porosity and/or roughness, which alter the capillary forces of the membrane surface, and thus the contact angle measurement [37].

Figure 3: Membrane hydrophobicity before and after being exposed to Milli-Q water, $\mathrm{NaOH}$ (pH 11.5), citric acidic (pH 2), SDS (10 mM) and EDTA (5.4 mM) at 20, 35 and $50{ }^{\circ} \mathrm{C}$. Error bars show standard deviation of five repetitive measurements.

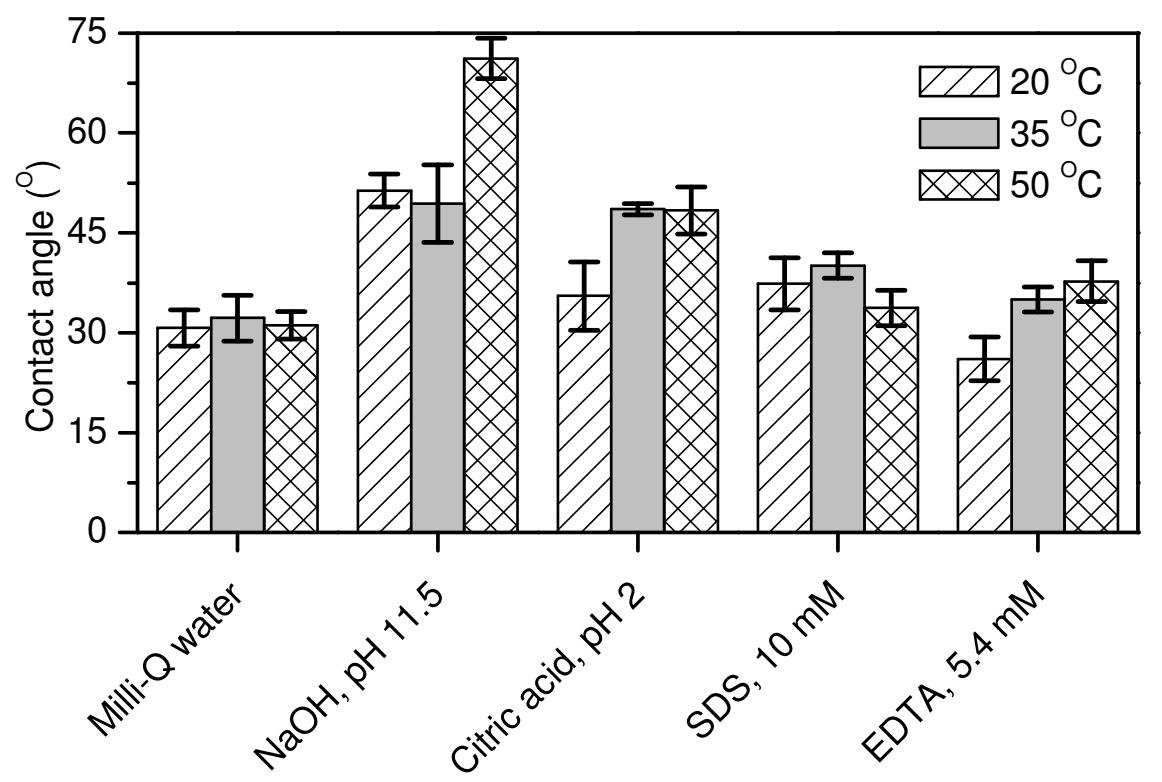

\subsection{4}

\section{Permeability}

The chemical cleaning temperature may exert a significant effect on the permeability of the NF270 membrane (Figure 4). When exposing the NF270 membrane to Milli-Q water at various temperatures (i.e. 20,35 , and $50{ }^{\circ} \mathrm{C}$ ) and in the absence of any chemical cleaning reagent, the membrane permeability decreased significantly as the temperature increased. This phenomenon was slightly further exacerbated with an acidic cleaning solution $(\mathrm{pH} 2)$ at 35 and $50{ }^{\circ} \mathrm{C}$. In contrast, when a caustic cleaning solution ( $\left.\mathrm{pH} 11.5\right)$ was used, the membrane permeability varied only slightly by temperature (Figure 4). Chemical cleaning with SDS significantly improved the permeability of the NF270 regardless of the cleaning temperature. On the other hand, EDTA cleaning at 20 and $35^{\circ} \mathrm{C}$ increased the permeability of the NF270, whereas, the opposite effect was observed at a cleaning temperature of $50{ }^{\circ} \mathrm{C}$ (Figure 4). 
The impacts of chemical cleaning by the four cleaning reagents and at different temperatures on the membrane permeability reported here are consistent with those previously reported by Nilsson et al [18]. In general, excessive chemical cleaning at an elevated temperature can reduce the membrane porosity by subsequent swelling and shrinking the membrane polymer $[18,34,35]$ and, acidic cleaning seems to lower the membrane porosity by neutralizing the membrane charge further. On the other hand, caustic cleaning can lead to the opposite effect by protonating dissociable functional groups, which can enlarge the membrane pores [22, 38]. It is noteworthy that a subsequently immersing of the cleaned membrane in a solution featuring the opposite $\mathrm{pH}$ might reverse the change in the polymeric matrix [24]. Because the rate of transport and chemical reaction can usually be enhanced at higher temperatures, the effect of caustic cleaning on the membrane permeability can also be amplified when the cleaning temperature increases. Our results demonstrate that cleaning temperature can potentially amplify the effect of chemical cleaning on the membrane permeability.

\section{[FIGURE 4]}

\subsubsection{FTIR Analysis}

FTIR analyses of the virgin and chemically cleaned NF270 membrane were conducted to determine if any chemical modifications of the membrane polymer matrix have occurred (Figure 5). The individual measured peaks and the associated chemical groups are summarised in Table 2. It is noteworthy that the NF270 has a relative thin active skin layer with approximately 15 - $40 \mathrm{~nm}$ [39], whereas, the penetration of an IR beam in an polymeric membrane sample can be significant deeper. Consequently, no peak of piperazine at a band of $1630 \mathrm{~cm}^{-1}$ was found in this study, whereas polysulphone peaks at 1586 and $1488 \mathrm{~cm}^{-1}$ were clearly discernible. No impact of cleaning temperature (i.e. 20,35 and $50^{\circ} \mathrm{C}$ ) or cleaning reagents (i.e. $\mathrm{NaOH}$, Citric acid, SDS and EDTA) could be observed in the FTIR spectra of the NF270 in this study (Figure 5). Zhu and Nyström [40] reported an additional peak at $1500 \mathrm{~cm}^{-1}$ after cleaning a polysulphone UF-membrane with $\mathrm{NaOH}$ at $80^{\circ} \mathrm{C}$. They suggested that $\mathrm{NaOH}$ could absorb the aromatic ether or hydrolyse the bond in the para-position of the ether connection. The cleaning temperature used by Zhu and Nyström [40] was significantly higher than what could be tolerated by a typical polyamide membrane. Thus, in contrast to the results by Zhu and Nyström [40], results reported in our study indicate that variations in surface roughness, hydrophobicity and permeability are likely due to physical changes of the active skin layer. Table 2: Assignments of FTIR peaks.

\begin{tabular}{|l|c|c|c|}
\hline $\begin{array}{l}\text { Wavenumber } \\
\left(\mathrm{cm}^{\square}\right)\end{array}$ & FTIR peak assignment & $\begin{array}{c}\text { Functional } \\
\text { group }\end{array}$ & Reference \\
\hline 1630 & Polypiperazinamide & Piperazine & {$[43]$} \\
\hline 1586 and 1488 & $\begin{array}{c}\text { Aromatic in-plane bend } \\
\text { stretching vibration }\end{array}$ & PSf & {$[39,43,44]$} \\
\hline 1544 & C-N stretching & PA & {$[43,44]$} \\
\hline
\end{tabular}




\begin{tabular}{|l|c|c|c|}
\hline 1329 and 1295 & Asymmetric $\mathrm{SO}_{2}$ stretching & PSf & {$[39,44]$} \\
\hline 1243 & Asymmetric C-O-C stretching & PES, PSf & {$[39,43,44]$} \\
\hline 1151 & Symmetric $\mathrm{SO}_{2}$ stretching & PES, PSf & {$[39,44]$} \\
\hline 1106 & $\begin{array}{c}\text { Aliphatic C-C/aromatic } \\
\text { hydrogen bending/rocking }\end{array}$ & PES, PSf & {$[44]$} \\
\hline$\sim 830$ & Para substituted phenyl groups & PSf & {$[43]$} \\
\hline
\end{tabular}

Figure 5: ATR-FTIR spectra of NF270 membrane samples before and after being exposed to Milli-Q water, $\mathrm{NaOH}(\mathrm{pH} 11.5)$, citric acidic (pH 2), SDS (10 mM) and EDTA (5.4 mM) at 20,35 and $50{ }^{\circ} \mathrm{C}$. Resolution was $1 \mathrm{~cm}^{-1}$. 

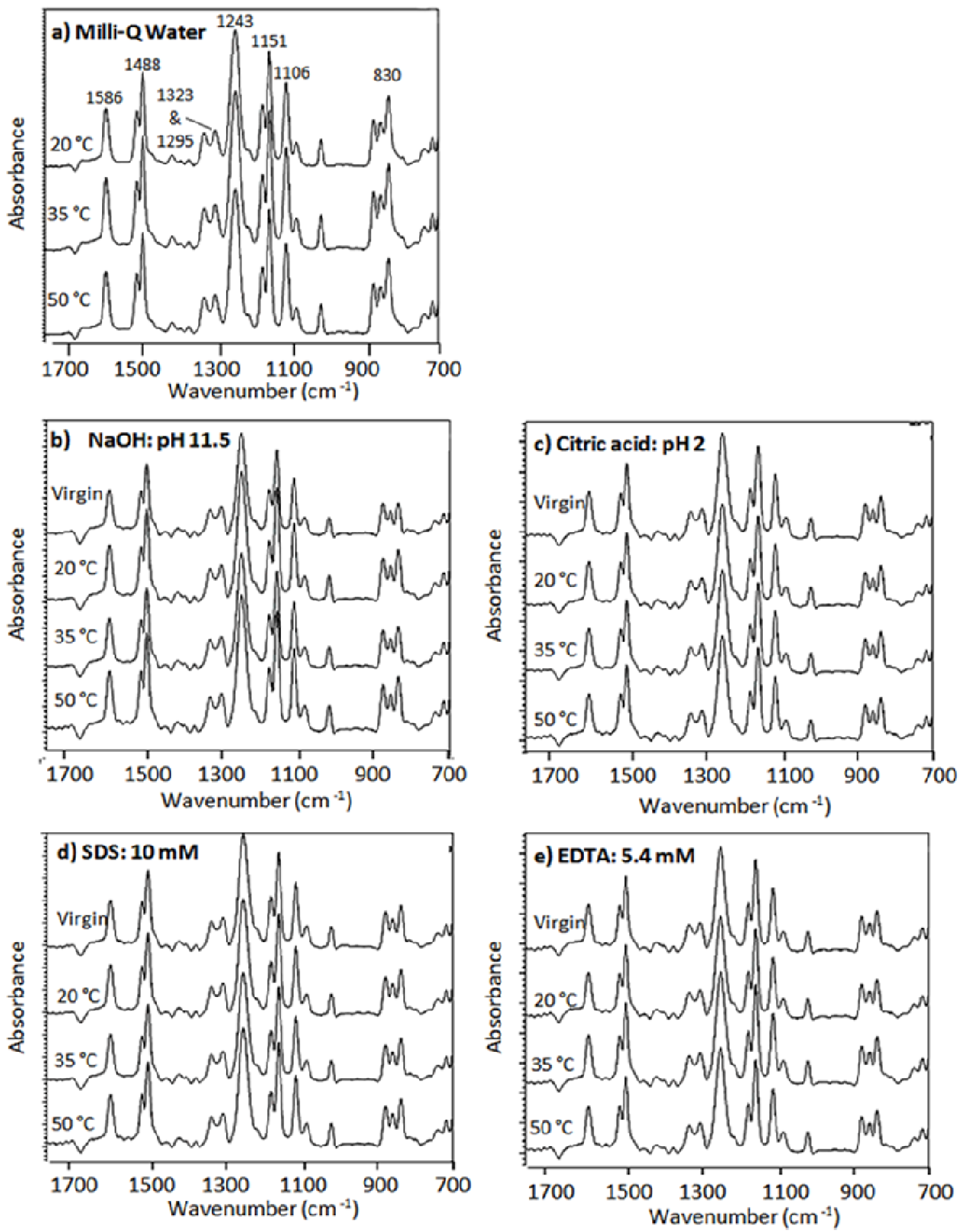

\subsection{Impact on Inorganic Salt and PhACs Rejection}

\subsubsection{Rejection of Salts}

Chemical cleaning at $20{ }^{\circ} \mathrm{C}$ using any of the four selected cleaning reagents had no significant impact on the rejection of conductivity or inorganic salts (Figure 6). Nevertheless, as the cleaning temperature increased to $50{ }^{\circ} \mathrm{C}$, a considerable increase in conductivity rejection was observed after acidic, SDS and EDTA cleaning throughout the $\mathrm{pH}$ range examined (Figure 
6c-e). In general, the rejection of salts by the virgin NF270 is governed by size exclusion and electrostatic interactions [19]. The conductivity rejection increased slightly as the feed solution $\mathrm{pH}$ increased since the membrane porosity and the surface charge (Figure 1), and thus the electrostatic interaction, are dependent on the solution $\mathrm{pH}$. However, because chemical cleaning at various temperatures did not significantly alter the membrane surface charge (section 3.1.1), the increase in conductivity rejection at an elevated temperature (i.e. 35 and $50{ }^{\circ} \mathrm{C}$ ) is likely the result of the membrane hysteresis phenomenon described above. The swelling and shrinking of the active skin layer of the NF270 membrane during chemical cleaning at an elevated temperature could possibly lead to a reduction in the membrane permeability or pore size, resulting in a subsequent increase in the rejection of inorganic salts. In good agreement with the results presented here, Mänttäri et al [41] also reported that glucose rejection by several NF-membranes increased after the feed temperature increased from 37 to $65{ }^{\circ} \mathrm{C}$ and then decreased back to $37^{\circ} \mathrm{C}$. The impact of cleaning temperature on conductivity rejection was not obvious during caustic cleaning (Figure 6b). This is because caustic cleaning can cause an increase in the membrane pore size, which then counterbalances the decrease in membrane pore size caused by the high cleaning temperature.

Figure 6: Conductivity rejection before and after being exposed to a) Milli-Q water, b) $\mathrm{NaOH}$ $(\mathrm{pH} 11.5), \mathrm{c})$ citric acidic ( $\mathrm{pH} 2)$, d) SDS (10 mM) and e) EDTA (5.4 mM) at 20, 35 and 50 ${ }^{\circ} \mathrm{C}$. Error bars show standard deviation of three repetitive measurements. The feed solution contained $1 \mathrm{mM} \mathrm{CaCl}_{2}, 20 \mathrm{mM} \mathrm{NaCl}$ and $1 \mathrm{mM} \mathrm{NaHCO}_{3}$. Cross flow velocity, permeate flow and temperature were $30.4 \mathrm{~cm} . \mathrm{s}^{-1}, 42 \mathrm{~L} \cdot \mathrm{m}^{-2} \mathrm{~h}^{-1}$ and $20 \pm 0.1^{\circ} \mathrm{C}$, respectively. 

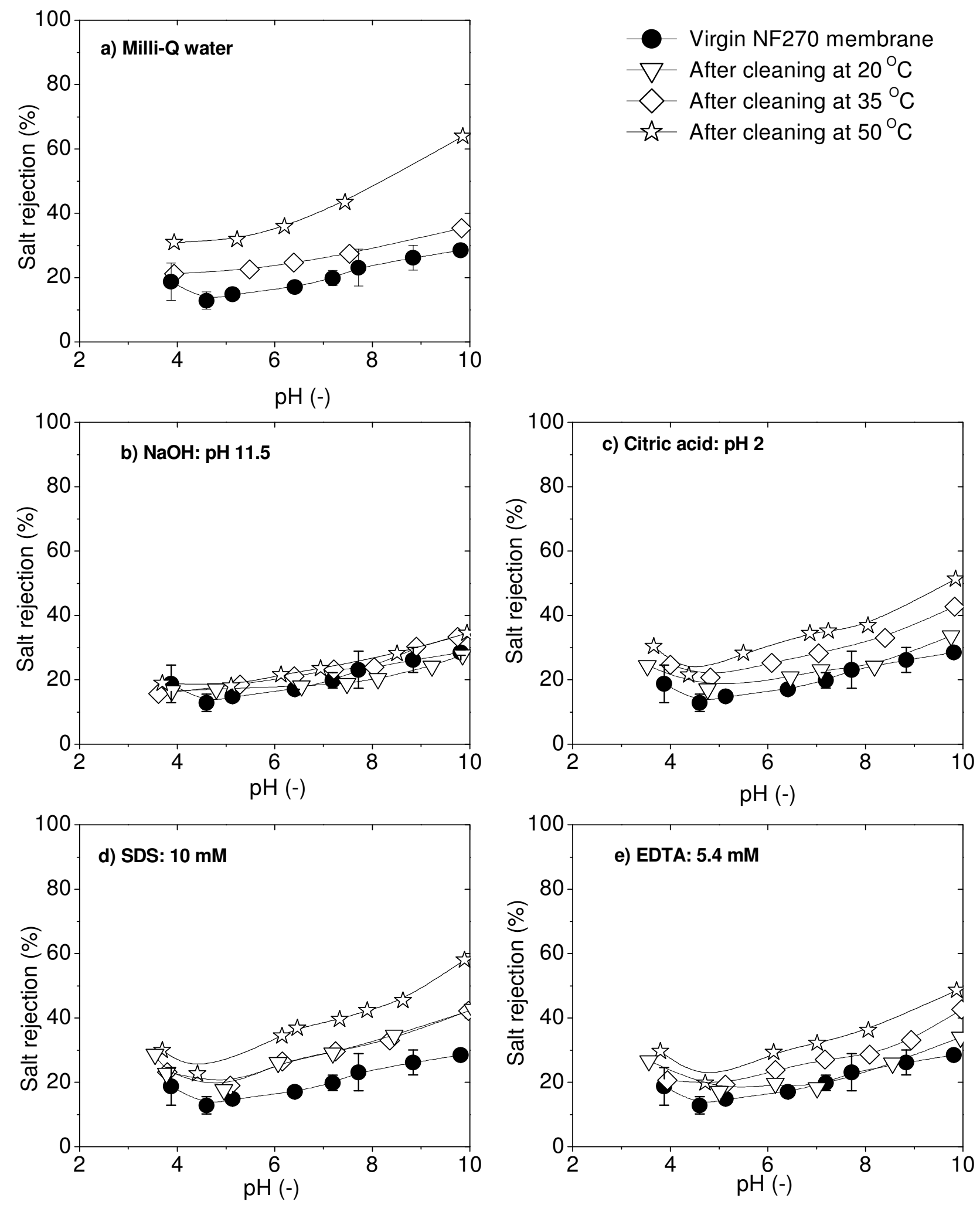

Figure 6 


\subsubsection{Rejection of PhACs}

Carbamazepine is a neutral and hydrophilic compound in the $\mathrm{pH}$ range from 4 to 10 examined in this study (Table 1). Thus, the rejection of carbamazepine by the NF270 is governed primarily by size exclusion. At all three cleaning temperatures of 20,35 , and $50{ }^{\circ} \mathrm{C}$ examined in this study, chemical cleaning resulted in a considerable increase in the rejection of carbamazepine with caustic cleaning being the only exception (Figure 7). These results are consistent with a previous study [22], which showed a small improvement in carbamazepine rejection by the NF270 membrane as a result of citric acid, SDS and EDTA cleaning. In addition, the results presented in Figure 7 also highlight the role of cleaning temperature in enhancing the impact of chemical cleaning on the rejection of carbamazepine by the NF270 membrane. The increase in carbamazepine rejection following chemical cleaning simulation using citric acid, SDS and EDTA was higher at elevated temperatures (i.e. 35 and $50{ }^{\circ} \mathrm{C}$ ) compared to an ambient cleaning temperature (Figure 6c-e). An increase in the cleaning temperature can enhance the interaction between the cleaning reagent and the membrane polymeric surface. In addition, as discussed above, the hysteresis effect caused by the increase and subsequent decrease in the cleaning temperature could tighten the membrane polymer and thus increasing the rejection of carbamazepine. In fact, a considerable increase in carbamazepine rejection could be observed when the membrane was exposed to a Milli-Q water solution at an elevated temperature, and no chemical cleaning reagent was used (Figure 7a). It is noteworthy that caustic cleaning had no discernible impact on the rejection of carbamazepine at all cleaning temperatures (Figure 7b). This is possibly because the shrinkage of the membrane polymer, due to an increased cleaning temperature (i.e. 35 and 50 ${ }^{\circ} \mathrm{C}$ ), was effectively compensated by the enlargement of pores caused by caustic cleaning [22].

Figure 7: Carbamazepine rejection before and after being exposed to a) Milli-Q water, b) $\mathrm{NaOH}(\mathrm{pH} 11.5), \mathrm{c})$ citric acidic (pH 2), d) SDS (10 mM) and e) EDTA (5.4 mM) at 20, 35 and $50{ }^{\circ} \mathrm{C}$. Error bars show standard deviation of three repetitive measurements. Experimental conditions were the same as shown in Figure 6. 


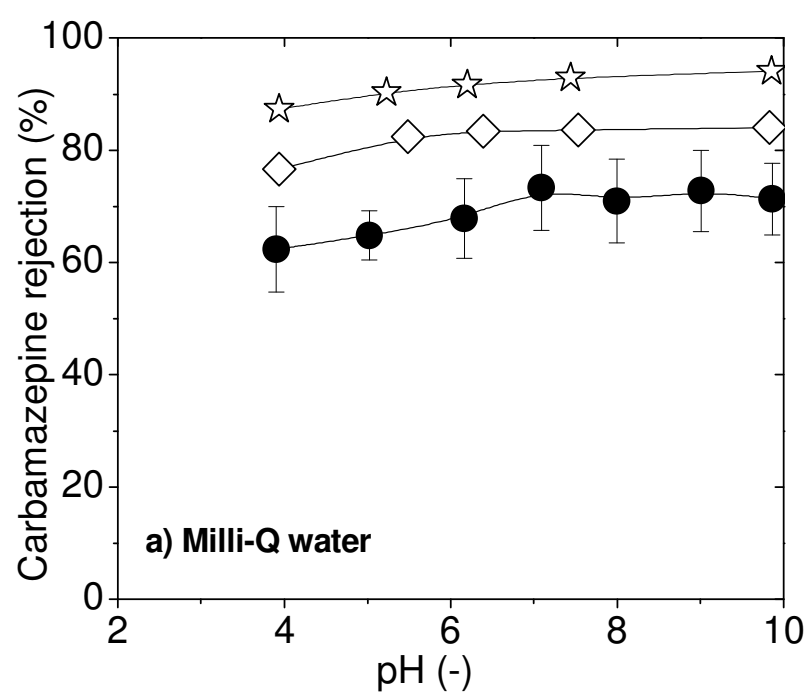

- Virgin NF270 membrane

$\nabla$ - After cleaning at $20{ }^{\circ} \mathrm{C}$

$\diamond$ After cleaning at $35^{\circ} \mathrm{C}$

$\rightarrow$ After cleaning at $50{ }^{\circ} \mathrm{C}$
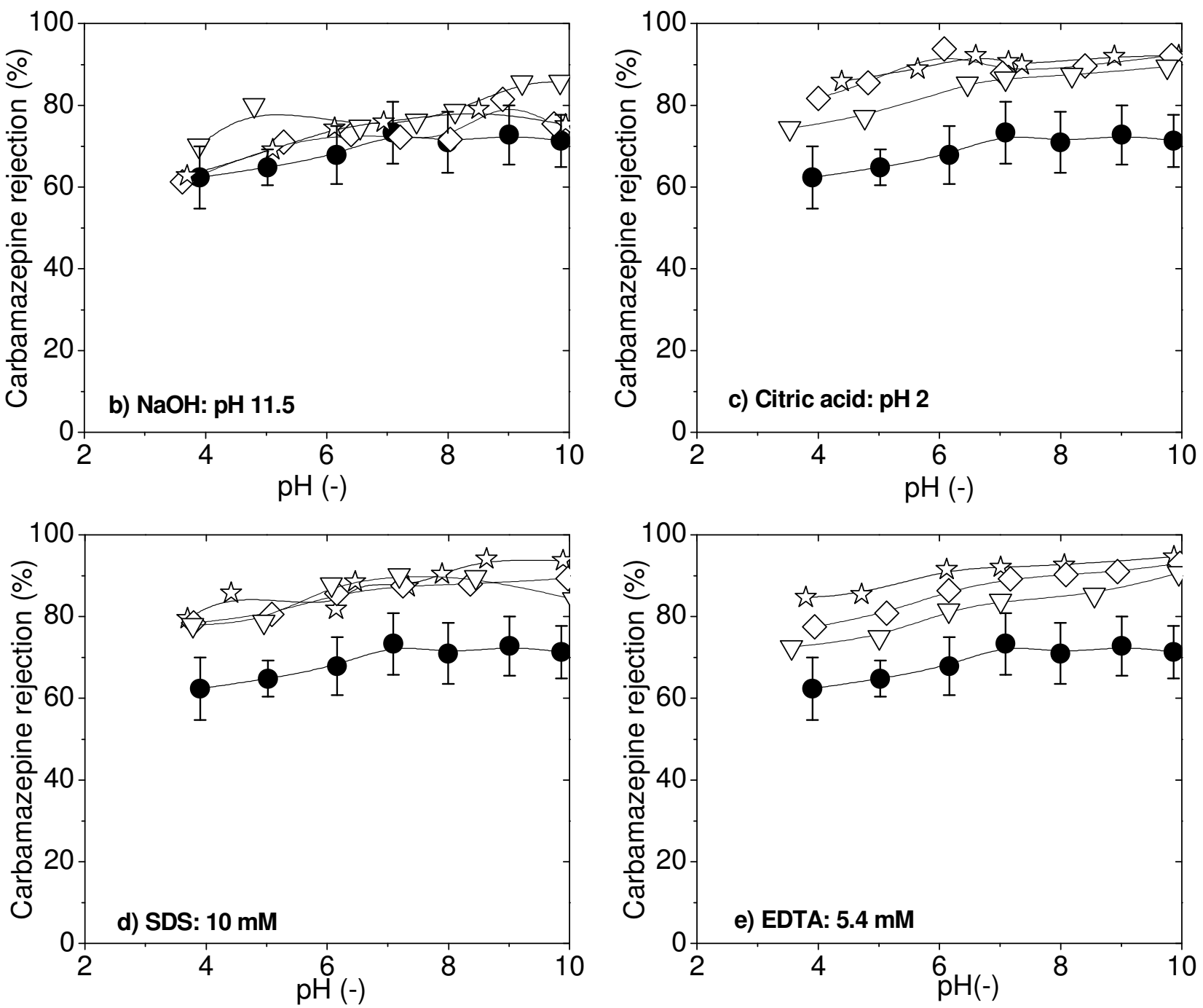

Figure 7

Unlike carbamazepine, sulfamethoxazole is an ionisable compound and can deprotonate at $\mathrm{pH}$ above the $\mathrm{pK}_{\mathrm{a}}$ value (i.e. 5.81) of the amino group of the compound. As a result, the rejection 
of sulfamethoxazole varies significantly as a function of the solution $\mathrm{pH}$ (Figure 8). In good agreement with several previous studies (e.g. [22, 42]), above $\mathrm{pH} 8$ when sulfamethoxazole is fully negatively charged, the rejection of sulfamethoxazole by the NF270 was almost $100 \%$. As the feed solution $\mathrm{pH}$ decreased, sulfamethoxazole rejection decreased sharply. At $\mathrm{pH} 4$, sulfamethoxazole exists primarily as a neutral species and is rejected by the virgin NF270 membrane just above $10 \%$.

Figure 8: Sulfamethoxazole rejection before and after being exposed to a) Milli-Q water, b) $\mathrm{NaOH}(\mathrm{pH} 11.5), \mathrm{c})$ citric acidic (pH 2), d) SDS (10 mM) and e) EDTA (5.4 mM) at 20, 35 and $50{ }^{\circ} \mathrm{C}$. Experimental conditions were the same as shown in Figure 6. 

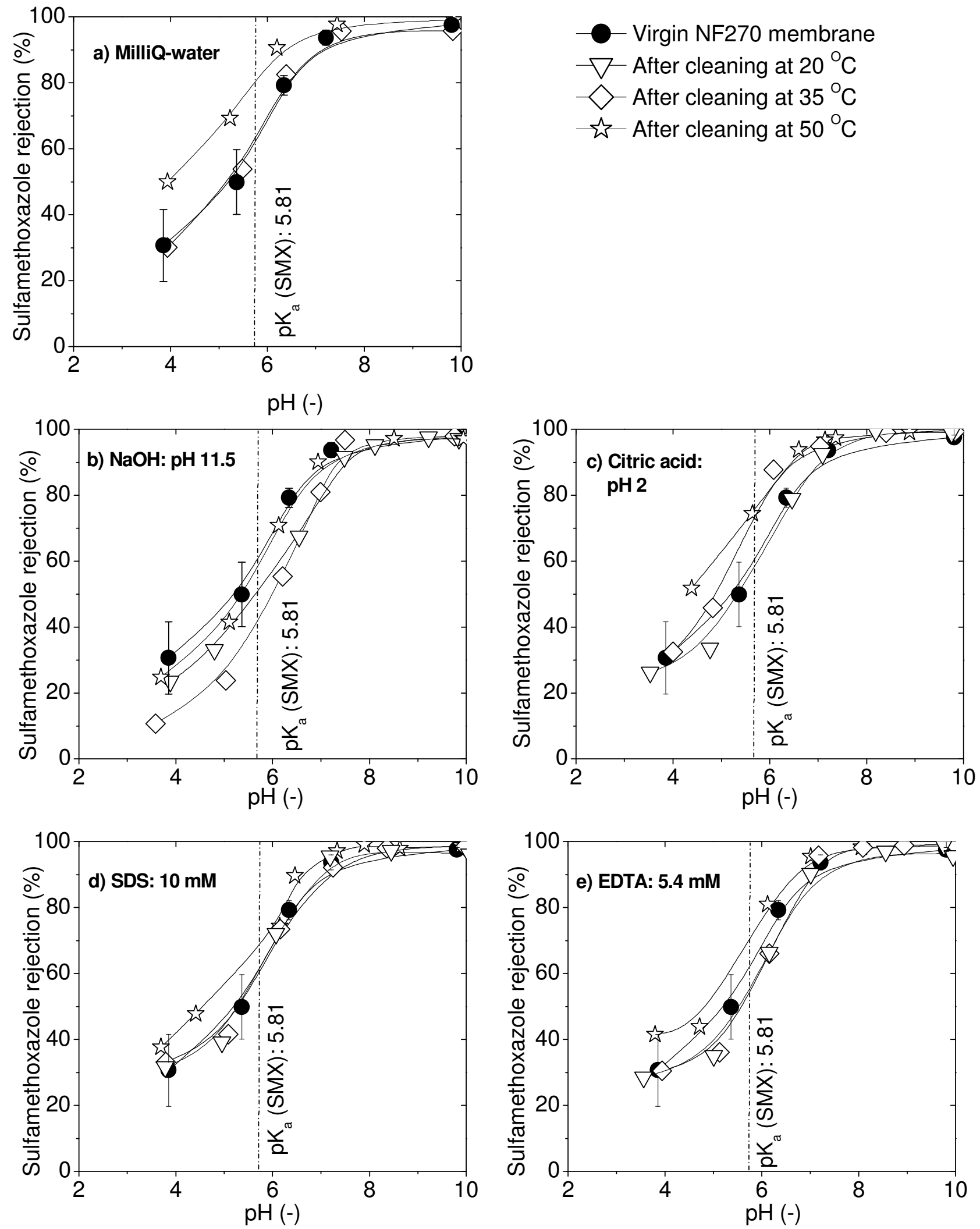

\section{Figure 8}

At $\mathrm{pH}$ above 8 , sulfamethoxazole is negatively charged and at this $\mathrm{pH}$, charge repulsion is the dominating rejection mechanism of this compound by the NF270 membrane. As discussed in 
section 3.1.1, chemical cleaning even at a high temperature did not result in any significant impact on the zeta potential of the membrane. Consequently, above $\mathrm{pH} \mathrm{8,} \mathrm{membrane} \mathrm{cleaning}$ at all three temperature values and with all chemical reagents did not result in any discernible effects on sulfamethoxazole rejection (Figure 8). As the feed solution $\mathrm{pH}$ decreased to 4, sulfamethoxazole is transformed from being negatively charged to neutral and correspondingly the predominant rejection mechanism changes from charge repulsion to size exclusion. Thus, the impact of cleaning temperature on neutral sulfamethoxazole rejection is similar to that with carbamazepine and conductivity as discussed above. The increase in neutral sulfamethoxazole rejection (at $\mathrm{pH} 4$ ) was highest when the cleaning was conducted at $50{ }^{\circ} \mathrm{C}$ (Figure 8). Once again, the impact of cleaning temperature on sulfamethoxazole rejection was masked and the rejection even slightly decreased when using a caustic cleaning reagent (Figure $8 b$ ).

\section{Conclusion}

The temperature used during chemical cleaning did not exert any discernible impact on the surface charge of the NF270 membrane. However, an elevated cleaning temperature can either amplify or reduce the impact of chemical cleaning on several other properties of the membrane (including hydrophobicity, surface roughness and permeability) as well as the rejection of both inorganic salts and PhACs. The influence of chemical cleaning on the membrane surface roughness was significantly enhanced when the cleaning temperature increased. Similarly, caustic and acidic cleaning aggravated the impact on the membrane surface hydrophobicity when the cleaning temperature increased. An increase in the cleaning temperature could also, to some extent, amplify the decrease in the membrane permeability as a result of acidic cleaning. In contrast, when a caustic cleaning solution ( $\mathrm{pH}$ 11.5) was used, the membrane permeability increased as the cleaning temperature increased. FTIR analysis suggests that chemical cleaning even at an elevated temperature did not permanently alter the chemical composition of the membranes. Indeed, the effects of chemical cleaning at a high temperature on the physicochemical properties of the membrane can be possibly attributed to the conformational changes of the membrane polymeric matrix. Chemical cleaning using aqueous acidic, SDS or EDTA solutions at elevated temperatures resulted in a considerable increase in the rejection of inorganic salts and PhACs in their neutral form. On the other hand, caustic cleaning at a high temperature had no measurable impact on the rejection of inorganic salts and neutral PhACs. It is hypothesized that caustic cleaning at elevated temperatures can cause opposing effects on the rejection of these solutes. At $\mathrm{pH}$ above 8, when sulfamethoxazole is negatively charged and rejected by charge repulsion, no discernible 
impact on the rejection of sulfamethoxazole could be observed by any chemical reagent and cleaning temperature.

\section{Acknowledgements}

This study was supported by the Australian Research Council Discovery Project DP0985389. Dow FilmTec (Minneapolis, MN, USA) is gratefully acknowledged for the donation of membrane samples to this research.

\section{References}

1. Schäfer AI, Fane AG, Waite TD. Nanofiltration, principles and application. 1st ed. Oxford, UK: Elsevier; 2005.

2. Lin AYC, Lin CF, Tsai YT, Lin HHH, Chen J, Wang XH, et al. Fate of selected pharmaceuticals and personal care products after secondary wastewater treatment processes in Taiwan. Water Sci Technol 2010; 62: 2450-8.

3. Ternes TA, Joss A, Siegrist H. Scrutinizing pharmaceuticals and personal care products in wastewater treatment. Environ Sci Technol 2004; 38: 392A-9A.

4. Zhao JL, Ying GG, Liu YS, Chen F, Yang JF, Wang L, et al. Occurrence and a screening-level risk assessment of human pharmaceuticals in the pearl river system, South China. Environ Toxicol Chem 2010; 29: 1377-84.

5. Mompelat S, Thomas $\mathrm{O}$, Le Bot B. Contamination levels of human pharmaceutical compounds in French surface and drinking water. J Environ Monit 2011; 13: 2929-39.

6. Valcárcel Y, González Alonso S, Rodríguez-Gil JL, Gil A, Catalá M. Detection of pharmaceutically active compounds in the rivers and tap water of the Madrid Region (Spain) and potential ecotoxicological risk. Chemosphere 2011; 84: 1336-48.

7. Lin AY-C, Panchangam SC, Ciou P-S. High levels of perfluorochemicals in Taiwan's wastewater treatment plants and downstream rivers pose great risk to local aquatic ecosystems. Chemosphere 2010; 80: 1167-74.

8. Ying G-G, Kookana RS, Kumar A, Mortimer M. Occurrence and implications of estrogens and xenoestrogens in sewage effluents and receiving waters from South East Queensland. Sci Total Environ 2009; 407: 5147-55.

9. Enick OV, Moore MM. Assessing the assessments: Pharmaceuticals in the environment. Environ Impact Asses 2007; 27: 707-29.

10. Yangali-Quintanilla V, Maeng SK, Fujioka T, Kennedy M, Amy G. Proposing nanofiltration as acceptable barrier for organic contaminants in water reuse. J Membr Sci 2010; 362: 334-45.

11. Nghiem LD, Schäfer AI, Elimelech M. Removal of Natural Hormones by Nanofiltration Membranes: $\square$ Measurement, Modeling, and Mechanisms. Environ Sci Technol 2004; 38: 1888-96.

12. Verliefde A, Cornelissen E, Amy G, Van der Bruggen B, van Dijk H. Priority organic micropollutants in water sources in Flanders and the Netherlands and assessment of removal possibilities with nanofiltration. Environ Pollut 2007; 146: 281-9. 
13. Simon A, Nghiem LD, Le-Clech P, Khan SJ, Drewes JE. Effects of membrane degradation on the removal of pharmaceutically active compounds (PhACs) by NF/RO filtration processes. J Membr Sci 2009; 340: 16-25.

14. Glater J, Hong S-k, Elimelech M. The search for a chlorine-resistant reverse osmosis membrane. Desalination 1994; 95: 325-45.

15. Porcelli N, Judd S. Chemical cleaning of potable water membranes: A review. Sep Purif Technol 2010; 71: 137-43.

16. Van der Bruggen B, Mänttäri M, Nyström M. Drawbacks of applying nanofiltration and how to avoid them: A review. Sep Purif Technol 2008; 63: 251-63.

17. Madaeni SS, Samieirad S. Chemical cleaning of reverse osmosis membrane fouled by wastewater. Desalination 2010; 257: 80-6.

18. Nilsson M, Trägårdh G, Östergren K. Influence of temperature and cleaning on aromatic and semi-aromatic polyamide thin-film composite NF and RO membranes. Sep Purif Technol 2008; 62: 717-26.

19. Nghiem LD, Schäfer AI, Elimelech M. Nanofiltration of Hormone Mimicking Trace Organic Contaminants. Separ Sci Technol 2005; 40: 2633-49.

20. Dow Chemicals, FILMTEC NF270-400 Nanofiltration Element. 2011; Available from: http://www.lenntech.com/Data-sheets/Dow-Filmtec-NF270-400.pdf.

21. Majamaa K, Warczok J, Lehtinen M. Recent operational experiences of FILMTEC (TM) NF270 membrane in Europe. Water Sci Technol 2011; 64: 228-32.

22. Simon A, Price WE, Nghiem LD. Effects of chemical cleaning on the nanofiltration of pharmaceutically active compounds (PhACs) Sep Purif Technol 2012; 88: 208-15.

23. Ang WS, Tiraferri A, Chen KL, Elimelech M. Fouling and cleaning of RO membranes fouled by mixtures of organic foulants simulating wastewater effluent. J Membr Sci 2011; 376: 196-206.

24. Al-Amoudi A, Lovitt RW. Fouling strategies and the cleaning system of NF membranes and factors affecting cleaning efficiency. J Membr Sci 2007; 303: 4-28.

25. Ang WS, Lee S, Elimelech M. Chemical and physical aspects of cleaning of organicfouled reverse osmosis membranes. J Membr Sci 2006; 272: 198-210.

26. Ang WS, Yip NY, Tiraferri A, Elimelech M. Chemical cleaning of RO membranes fouled by wastewater effluent: Achieving higher efficiency with dual-step cleaning. J Membr Sci 2011; 382: 100-6.

27. Al-Amoudi A, Williams P, Mandale S, Lovitt RW. Cleaning results of new and fouled nanofiltration membrane characterized by zeta potential and permeability. Sep Purif Technol 2007; 54: 234-40.

28. Al-Amoudi A, Williams P, Al-Hobaib AS, Lovitt RW. Cleaning results of new and fouled nanofiltration membrane characterized by contact angle, updated DSPM, flux and salts rejection. Appl Surf Sci 2008; 254: 3983-92.

29. Kang G, Gao C, Chen W, Jie X, Cao Y, Yuan Q. Study on hypochlorite degradation of aromatic polyamide reverse osmosis membrane. J Membr Sci 2007; 300: 165-71.

30. Ettori A, Gaudichet-Maurin E, Schrotter J-C, Aimar P, Causserand C. Permeability and chemical analysis of aromatic polyamide based membranes exposed to sodium hypochlorite. J Membr Sci 2011; 375: 220-30. 
31. Mariam T, Nghiem LD. Landfill leachate treatment using hybrid coagulationnanofiltration processes. Desalination 2010; 250: 677-81.

32. Vogel D, Simon A, Alturki AA, Bilitewski B, Price WE, Nghiem LD. Effects of fouling and scaling on the retention of trace organic contaminants by a nanofiltration membrane: the role of cake-enhanced concentration polarisation. Sep Purif Technol 2010; 73: 256-63.

33. Childress AE, Elimelech M. Relating Nanofiltration Membrane Performance to Membrane Charge (Electrokinetic) Characteristics. Environ Sci Technol 2000; 34: 3710-6.

34. Goosen MFA, Sablani S, Cin MD, Wilf M. Effect of Cyclic Changes in Temperature and Pressure on Permeation Properties of Composite Polyamide Seawater Reverse Osmosis Membranes. Separ Sci Technol 2011; 46: 14-26.

35. Mänttäri M, Pihlajamäki A, Kaipainen E, Nyström M. Effect of temperature and membrane pre-treatment by pressure on the filtration properties of nanofiltration membranes. Desalination 2002; 145: 81-6.

36. Bowen WR, Doneva TA, Stoton JAG. The use of atomic force microscopy to quantify membrane surface electrical properties. Colloid Surface A 2002; 201: 73-83.

37. Keurentjes JTF, Harbrecht JG, Brinkman D, Hanemaaijer JH, Cohen Stuart MA, van't Riet K. Hydrophobicity measurements of microfiltration and ultrafiltration membranes. J Membr Sci 1989; 47: 333-44.

38. Liikanen R, Yli-Kuivila J, Laukkanen R. Efficiency of various chemical cleanings for nanofiltration membrane fouled by conventionally-treated surface water. J Membr Sci 2002; 195: 265-76.

39. Freger V, Gilron J, Belfer S. TFC polyamide membranes modified by grafting of hydrophilic polymers: an FT-IR/AFM/TEM study. J Membr Sci 2002; 209: 283-92.

40. Zhu H, Nyström M. Cleaning results characterized by flux, streaming potential and FTIR measurements. Colloid Surface A 1998; 138: 309-21.

41. Mänttäri M, Pekuri T, Nyström M. NF270, a new membrane having promising characteristics and being suitable for treatment of dilute effluents from the paper industry. J Membr Sci 2004; 242: 107-16.

42. Simon A, Price WE, Nghiem LD. Implications of membrane fouling toward the removal of the pharmaceutical sulfamethoxazole by nanofiltration processes. Zhejiang Univ Sci A 2011; 12: 575-82.

43. Tang CY, Kwon Y-N, Leckie JO. Effect of membrane chemistry and coating layer on physiochemical properties of thin film composite polyamide RO and NF membranes: I. FTIR and XPS characterization of polyamide and coating layer chemistry. Desalination 2009; 242: 149-67.

44. Bui N-N, Lind ML, Hoek EMV, McCutcheon JR. Electrospun nanofiber supported thin film composite membranes for engineered osmosis. J Membr Sci 2011; 385-386: 10-9. 